\title{
POLÍTICAS PÚBLICAS DE INFORMAÇÃO E TECNOLOGIA: INFLUÊNCIAS MIDIÁTICAS
}

\section{ARTIGO ORIGINAL}

STUMPF, Katiusa ${ }^{1}$

STUMPF, Katiusa. Políticas públicas de informação e tecnologia: influências midiáticas. Revista Científica Multidisciplinar Núcleo do Conhecimento. Ano 05, Ed. 06, Vol. 07, pp. 144-170. Junho de 2020. ISSN: 2448-0959, Link de acesso: https://www.nucleodoconhecimento.com.br/comunicacao/influencias-

\section{$\underline{\text { midiaticas }}$}

\section{RESUMO}

Este trabalho é sobre o poder da informação na sociedade contemporânea, destacando-se as relações de poder midiático que se dão neste contexto e as possibilidades de progresso social por meio de políticas públicas de informação e tecnologia comprometidas com os cidadãos. Tendo como método a pesquisa bibliográfica, é desenvolvida uma revisão de literatura possibilitando a discussão acerca das transformações políticas e sócio-culturais que se dão a partir do advento das novas tecnologias de informação e de comunicação das últimas décadas. Com o objetivo de refletir sobre essas questões, destaca-se o acesso à informação por meio de tais tecnologias como possibilidade de fortalecimento da cidadania. Primeiramente são apresentadas algumas definições e ênfase da utilidade de políticas públicas de informação e tecnologia. Em seguida é tratada a questão da influência midiática em políticas públicas de informação e o papel social do profissional bibliotecário nesse panorama. Por fim são apresentadas algumas considerações finais.

${ }^{1}$ Mestre em Ciência da Informação - UFSC. 
Palavras-chave: Políticas Públicas de Informação, informação e tecnologia, influências midiáticas, profissional bibliotecário.

\section{INTRODUÇÃO: DEFINIÇÃO E ÊNFASE NA UTILIDADE DE POLÍTICAS PÚBLICAS DE INFORMAÇÃO E TECNOLOGIA}

Políticas públicas se referem a diretrizes que são elaboradas com o intuito de se resolver problemas considerados da esfera pública (SECCHI, 2012). Dizem respeito ao "conjunto de programas de ação governamental voltados à concretização de direitos sociais". Caracterizam-se "[...] como um instrumento de planejamento, racionalização e participação popular" (LIRA; OLIVEIRA, 2005, p. 7). Isto é, as políticas públicas consistem em um conjunto de ações (diretrizes) que envolvem simultaneamente o estado e a sociedade visando o bem comum e não apenas os desejos de um único governante e o lucro acima de tudo. O termo público encontrase relacionado a todos os cidadãos e não apenas ao Estado em si. É por meio da política pública que se busca o atendimento das necessidades sociais de forma a incluir e permitir que todo cidadão tenha voz, ou seja, tenha seu direito de opinião e manifestação respeitado.

Assim, as Políticas públicas emanam de uma autoridade pública, a qual tem o papel de instituir e legalizar os direitos sociais advindos da sociedade. Tais políticas são concretizadas por meio de produtos e serviços, não visam o lucro e sim o bem estar social. Ressalta-se que nem toda medida tomada pelo governo é uma política pública, haja vista que algumas medidas são tomadas para sanar problemas pontuais da sociedade como, por exemplo, corte de relações diplomáticas com outro país devido à discordância em assuntos estratégicos (segurança internacional).

A formulação de Políticas públicas envolve um ciclo. Tal ciclo é "um esquema de visualização e interpretação que organiza a vida de uma Política pública em fases sequenciais e interdependentes" (SECCHI, 2012). Segundo Secchi (2012), as fases são as seguintes: identificação do problema; formação da agenda; formulação de alternativas; tomada de decisão; implementação; avaliação; e extinção. 
Ao se fazer a identificação do problema, busca-se a discrepância entre o status quo e a situação ideal possível. Pode surgir subitamente (epidemias); lentamente (congestionamento de trânsito) ou ciclicamente (secas). A formação da agenda é um conjunto de problemas ou temas vistos como relevantes. Pode ser subdividida em: agenda da mídia: que é conjunto de problemas ou temas que recebem especial atenção dos diversos meios de comunicação; agenda política: que diz respeito ao conjunto de problemas que a comunidade política percebe como merecedor de intervenção pública; e a agenda formal: são problemas que o poder público já decidiu enfrentar. Já a formulação de alternativas é a fase de construção e combinação de soluções ao problema identificado. É nesta fase que são estabelecidos os objetivos, estratégias, tentando-se projetar as consequências de cada alternativa. Depois, passa-se a tomada de decisão, neste momento que é escolhida a alternativa de Política pública, ou seja, a decisão de Política Pública é formalizada. Ressalta-se que em todas as fases são necessárias tomadas de decisão. Sequencialmente, vem a implementação. Nesta fase as regras, rotinas e processos sociais são convertidos de intenções em ações. Existem dois modelos de implementação denominados de topdown e bottom-up. A avaliação se refere ao processo de julgamento sobre a validade das propostas para a ação pública. A avaliação ocorre em três momentos: avaliação ex ante: antes da implementação; avaliação ex post: depois da implementação; avaliação in itinere: que é o monitoramento. Existem três elementos que devem ser considerados no processo de avaliação de políticas públicas: critérios (mecanismos lógicos que servem como base para escolhas ou julgamentos), indicadores (artifícios (proxies) criados para operacionalizar os critérios) e padrões (parâmetros que dão referência comparativa aos indicadores). E, por fim, a extinção. As causas da extinção de uma política pública são variadas, as mais freqüentes são: quando o problema inicial é resolvido; quando os programas ou leis são avaliados como ineficazes; quando o problema inicial perdeu progressivamente a sua importância; e quando a política pública possui "prazo de validade", sendo extintas no fim do prazo estipulado. 
Figura 1: Ciclo de Políticas públicas.

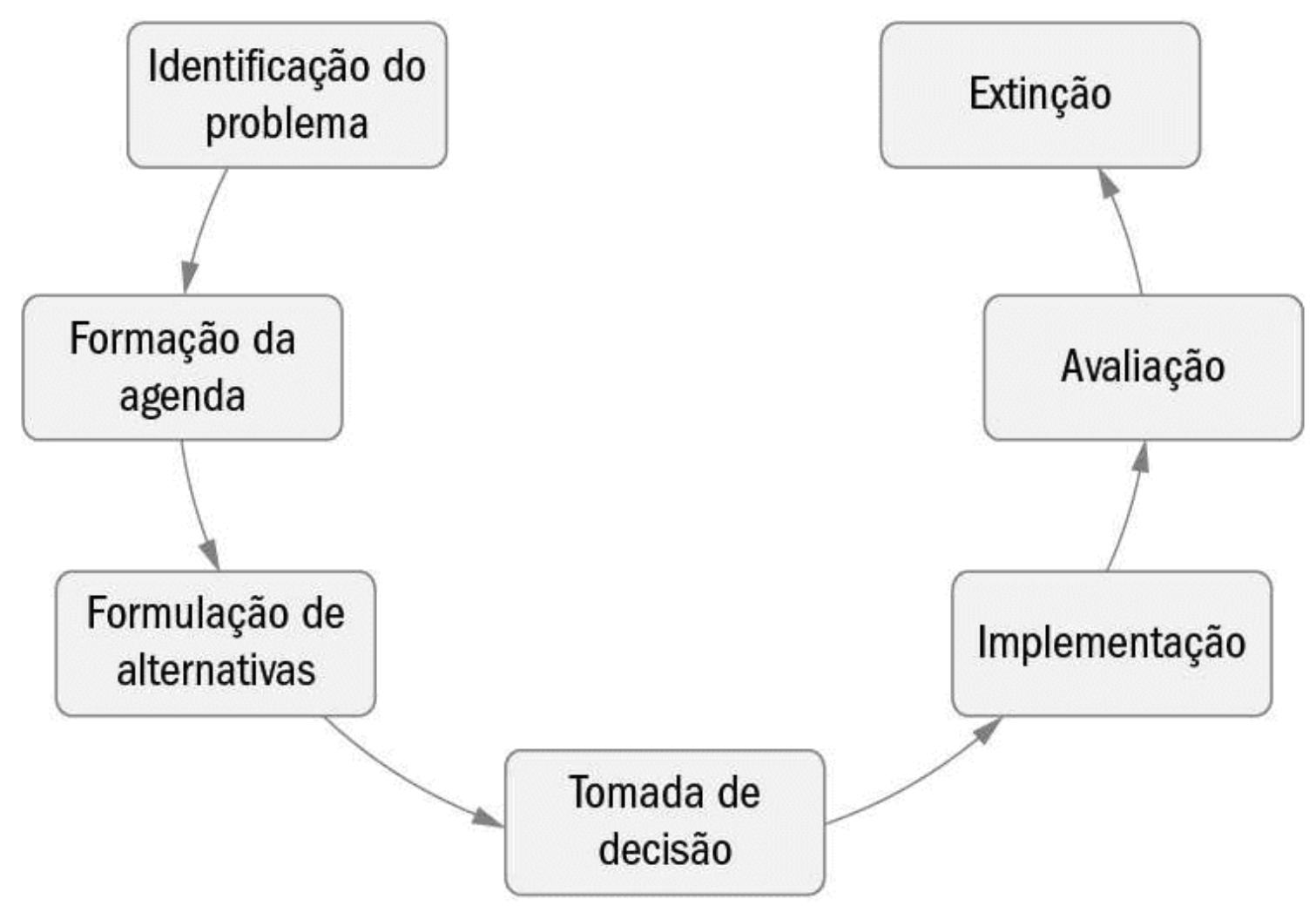

Fonte: SECCHI (2012).

É nesse contexto que estão inseridas as Políticas públicas de informação e tecnologia enquanto diretrizes para o pleno desenvolvimento das sociedades e de seus cidadãos. Parte-se do pressuposto de que o acesso a informação é um direito social, isso implica que todos os cidadãos têm direito ao acesso e utilização a esse insumo primordial ao seu desenvolvimento, tanto como pessoa quanto elemento transformador da sociedade. Conforme a Declaração Universal dos Direitos Humanos de 1948 em seu artigo 19, quando estabelece o direito a informação, todas as pessoas têm o direito de "[...] procurar, receber e difundir, sem consideração de fronteiras, as informações e idéias por qualquer meio de expressão". Assim, um dos principais objetivos de qualquer sociedade, que luta pelo desenvolvimento humano, é o fortalecimento dos indivíduos que a compõem, por meio do acesso e utilização da informação e do conhecimento (UHLIR, 2006). Portanto, para garantir o acesso igualitário dos cidadãos a essa importante ferramenta, a informação, surge nos governos a preocupação de uma política pública voltada à informação. 
Carvalho (2010) define Política pública de informação e tecnologia como "uma decisão governamental, que regula todas as atividades do setor e é resultado de uma correlação de forças dentro do âmbito do Estado". Elas indicam estratégias e programas cujos objetivos é o de proporcionar o desenvolvimento e utilização ótimos de recursos, serviços e sistemas de informação pelos diversos atores e campos da sociedade. Para tanto, utiliza-se conhecimentos e profissionais especializados, informação científica, técnica, social e econômica, disponíveis internamente nos países e em outros lugares do mundo, com o intuito de solucionar os mais diversos problemas e, principalmente, para o desenvolvimento de todos os setores que envolvem a sociedade, já que "uma política nacional de informação plenamente incorporada ao plano nacional de desenvolvimento, é essencial ao desenvolvimento socioeconômico do país. Todos os produtos e serviços são estabelecidos com o intuito de responder às necessidades de informação de todos os cidadãos" (MONTVILLOF, 1990, p. 11).Está implícita nas diretrizes das políticas públicas de informação e tecnologia a participação dos cidadãos, das esferas públicas, privadas e sociedade civil, nas decisões políticas do Estado. Sua participação é de suma importância para o pleno funcionamento de tais políticas, já que aos cidadãos elas são previamente direcionadas.

Quanto maior a possibilidade de os cidadãos poderem discernir se os governantes estão agindo em função do interesse da coletividade e sancioná-los apropriadamente, mais accountable é um governo, com decisores governamentais prestando contas de suas ações, garantindose maior transparência e a exposição pública das políticas (LIRA; OLIVEIRA, 2005).

Questões relacionadas à política pública de informação e tecnologia emergem como "[...] tema e domínio relativamente autônomo, em nível nacional e internacional, no cenário do pós-guerra, associada às políticas de ciência e tecnologia" (GONZÁLEZ DE GÓMEZ, 2002, p. 27). O relacionamento entre política e informação começa na década de 1950 a ser inserido em programas de governo e de políticas públicas (GONZÁLEZ DE GÓMEZ, 2002). Jardim (1995, p. 19) cita dois fatos principais que 
indicam esse panorama, quais sejam: o "Weinberg Report" (U.S. President's Science and Advisory Commitee, 1963), advindo dos Estados Unidos, que define como escopo e abrangência de uma política de informação a transferência de informação científica, sob a responsabilidade do governo; e as agendas internacionais estabelecidas pela Organização das Nações Unidas para a Educação, Ciência e Cultura (Unesco) que dirigiam-se ao estabelecimento de um programa intergovernamental e cooperativo visando promover e otimizar o acesso e uso da informação, superando as brechas científico-informacionais existentes entre os países centrais e periféricos, sendo estes últimos o foco principal.

Neste sentido, percebe-se que as políticas públicas de informação e tecnologia consistem na valoração da informação como instrumento para a transformação social, possibilitando por meio do acesso da mesma, a formação de cidadãos questionadores da realidade em que se encontram inseridos. É de suma importância para o desenvolvimento econômico e social de uma sociedade, principalmente nos dias atuais, já que o desenvolvimento está intimamente ligado ao conhecimento e as novas tecnologias, uma vez que vivemos inseridos na chamada "sociedade da informação".

O termo sociedade da informação destaca o papel desta última na sociedade. Sustentarei, porém, que a informação, em seu sentido mais amplo, ou seja, como 'comunicação do conhecimento', tem sido fundamental em todas as sociedades, incluída a Europa medieval, que estava estruturada e em certa medida unificada em torno do escolasticismo, isto é, em conjunto, um marco intelectual... Em contraste, o termo informacional indica o atributo de uma forma específica de organização social na qual a geração, processamento e transmissão da informação convertem-se em fontes fundamentais da produtividade e do poder, devido às novas condições tecnológicas que surgem neste período histórico (CASTELLS, 1997, p. 47).

Assim, cabe ao governo assegurar o acesso universal às tecnologias de informação e comunicação, independentemente de situação social e localização do cidadão. Ou seja, assegurar níveis básicos de serviços, viabilizar a participação de minorias sociais 
e segmentos marginalizados, de maneira que os benefícios que a sociedade da informação pode proporcionar estejam a seu alcance.

$\mathrm{Na}$ era da Internet, o Governo deve promover a universalização do acesso e o uso crescente dos meios eletrônicos de informação para gerar uma administração eficiente e transparente em todos os níveis. A criação e manutenção de serviços equitativos e universais de atendimento ao cidadão contam-se entre as iniciativas prioritárias da ação pública [...] (TAKAHASHI, 2000, p. 5.).

Porém, ressalta-se que somente assegurar o acesso e uso das tecnologias de informação não viabiliza efetivamente que os cidadãos se insiram na denominada sociedade da informação. Outros desafios devem ser superados, como por exemplo, o analfabetismo de grande parte da população dos países em desenvolvimento. Além disso, como destaca Takahashi (2000, p. 8):

Questão estratégica nas políticas e programas de inserção na sociedade da informação é - além de cuidar do uso adequado das tecnologias aumentar a quantidade e a qualidade de conteúdos nacionais que circulam nas redes eletrônicas e nas novas mídias. O amparo às identidades culturais nos novos meios resultará em benefícios evidentes, na forma de incremento da atividade econômica em geral e de desenvolvimento da cidadania.

Observa-se que mesmo diante da importância dada às políticas públicas de informação e tecnologia para o desenvolvimento da sociedade como um todo (cultural, econômico, social, por exemplo), principalmente para aquelas de países em desenvolvimento, como os da América Latina, os gestores dos Estados pouco tem explorado esse campo e, quando as têm, não chegam a colocá-las em prática ou não chegam a cumprir com os objetivos propostos. Tais gestores acreditam que as políticas referentes à informação dizem respeito a questões consideradas pouco compreensivas, intangíveis e até menos urgentes para a população (CUBILLO, 2003). Cubillo (2003), depois de realizar uma pequena investigação a respeito das políticas 
públicas de informação na América Latina, constatou que é desolador o panorama encontrado, já que poucas foram as políticas efetivamente colocadas em prática e que geraram bons resultados. Para o autor tem sido muito difícil para as organizações públicas da América Latina cumprir com a sua missão primordial que é a promoção do uso adequado da informação, do conhecimento e da comunicação devido às influências externas advindas de outros países, por exemplo.

Este é um fato que tem, de certo modo, se apresentado no Brasil. Poucas são as políticas públicas de informação desenvolvidas e implementadas no país e que tiveram ou tem algum reflexo positivo na sociedade brasileira. O Programa Brasileiro para a Sociedade da Informação, mais conhecido como Livro Verde, é uma delas, cujo objetivo foi lançar as bases da Sociedade da Informação no Brasil, ou seja, desenvolver programas de metas e ações que levariam ao estabelecimento de tal sociedade, como instituição da inclusão digital e a infra-estrutura necessária para a disseminação de informação e conteúdos digitais (NEVES, 2010). O programa foi aprovado pelo Conselho Nacional de Ciência e Tecnologia, em dezembro de 1998, refletindo em propostas, posteriormente, pelo Ministério da Ciência e Tecnologia no Plano Plurianual de 2000 a 2003 (TAKAHASHI, 2000). O documento, isto é, o Livro Verde,

[...] se reveste de pelo menos duas características inusitadas, quando comparado com documentos similares de outros países: $1^{\underline{a}}$ ) a proposta do Grupo tenta cobrir, de forma articulada e abrangente, todos os aspectos considerados relevantes para a Sociedade da Informação no Brasil, de P\&D a aplicações, do setor governamental ao setor privado, de tecnologias avançadas a impacto social; $2^{\mathrm{a}}$ ) a proposta do Grupo tenta chegar até o nível de ações concretas, visando a enriquecer as discussões subsequentes para a consolidação de um plano final no Livro Branco (TAKAHASHI, 2000, p. XV).

Considerado uma das políticas de informação mais importantes já desenvolvidas no Brasil, o Livro Verde, até o momento, não chegou a sua fase final de aplicação, ou seja, em ações concretas que culminaria no desenvolvimento e consolidação do 
programa no denominado Livro Branco. Constata-se que este processo está ainda em andamento no país.

Desde a implantação do Programa Sociedade da Informação no Brasil Livro Verde - o Estado brasileiro tem apresentado alternativas para uma efetiva implementação da sociedade da informação no país. No entanto, em muitos momentos, percebe-se a incapacidade do Estado em gerir essas alternativas [...] (CARVALHO, 2010, p. 86).

Isso ocorre devido ao fato de que existe certa divergência dos objetivos e metas almejados pelo governo federal e as características reais apresentadas pela sociedade brasileira, como o analfabetismo, por exemplo, o que influencia negativamente os resultados esperados pelos gestores (FERREIRA, 2003).

Outras Políticas públicas de informação também foram implementadas no Brasil, não menos importantes, como, por exemplo: o Plano Nacional do Livro e Leitura (PNLL). O PNLL foi instituído em 2005 com o intuito de melhorar a capacidade de leitura dos cidadãos brasileiros bem como permitir que a leitura faça parte da vida dos mesmos.

O objetivo central da Política de Estado aqui delineada é o de assegurar e democratizar o acesso à leitura e ao livro a toda a sociedade, com base na compreensão de que a leitura e a escrita são instrumentos indispensáveis na época contemporânea para que o ser humano possa desenvolver plenamente suas capacidades, seja individual ou coletivamente. Há a conviç̧ão de que somente assim é possível que, na sociedade da informação e do conhecimento, o indivíduo exerça de maneira integral seus direitos, participe efetivamente dessa sociedade, melhore, em amplo sentido, seu nível educativo e cultural, fortaleça os valores democráticos, seja criativo, conheça os valores e modos de pensar de outras pessoas e culturas e tenha acesso às formas mais verticais do conhecimento e à herança cultural da humanidade. Trata-se de intensa valorização dos caminhos abertos ao indivíduo pela cultura 
escrita, sem que se deixe de reconhecer e se tente apoiar e preservar a cultura oral de nosso povo (BRASIL, 2005).

Essa é uma política pública que vem sendo aprimorada e outras políticas, a partir desta, sendo implementadas em planos estaduais (PELL - Política Estadual do Livro e Leitura) e municipais (PMLL - Política Municipal do Livro e Leitura). Porém, o que se percebe é que na prática pouco se tem avançado. $O$ que existe é uma imensa propaganda nas mídias brasileiras sobre os pontos positivos apresentados por tais planos que no cotidiano das escolas pouco se verifica. Exemplo disso é a falta de bibliotecas nas escolas e quando estas instituições as têm não possuem profissionais qualificados, os bibliotecários, os quais são de suma importância para se alcançar os objetivos almejados pelo PNLL.

\section{INFLUÊNCIAS MIDIÁTICAS EM POLÍTICAS PÚBLICAS DE INFORMAÇÃO E TECNOLOGIA}

Com o avanço das tecnologias que emergiram após a Segunda Guerra Mundial, logo a humanidade desenvolveu-se rumo a um progresso maior. Surgiram às grandes redes para comunicação modificando a forma de como as informações são repassadas. Estabeleceu-se o modelo de economia global baseado na informação e no conhecimento. Trata-se da Era da Informação, na qual estar bem informado e, com isso, poder refletir acerca dos fatos é de fundamental importância para a concretização de um indivíduo como cidadão pertencente e participante da sociedade na qual está inserido.

Entretanto, estas transformações sociais não aconteceram da mesma forma e com a mesma intensidade em todas as partes do globo. Neste sentido e, para ilustrar um pouco destas disparidades sociais, pode-se destacar como um bom exemplo da deficiência informacional e suas implicações para uma sociedade, a abordagem de Asne Seierstad (2006), ao retratar a sociedade afegã através dos três meses em que a jornalista norueguesa, que estava cobrindo a guerra com os talibãs, conviveu com uma família do Afeganistão, tendo sido hospedada na casa de um livreiro que lutava para não ser obrigado a fechar sua livraria. A autora destaca a situação da mulher 
perante o autoritarismo masculino e a tradição patriarcal do Afeganistão, a dificuldade de acesso a leitura por parte do povo afegão e, principalmente pelas mulheres, além do fato de muitas crianças viverem sem escola e, portanto, sem o aprendizado da leitura e o incentivo para a mesma. Vale salientar que tais acontecimentos ocorrem em pleno século XXI em meio à chamada sociedade da informação e do conhecimento.

Em contraste, pode-se destacar a obra de Manguel (2006) que, por outro lado, retrata o século XIV, quando são poucos os leitores, poucos os livros e poucas as pessoas que sabem ler, mas mesmo assim o autor idealiza a liberdade de ir além do direito a leitura e pensar até mesmo na possibilidade de livros que poderiam vir a existir sobre temas, os mais diversos.

Destes exemplos observa-se a questão do acesso à leitura e à informação. Em dois momentos históricos distantes e, portanto, com contextos extremamente distintos, está presente a exclusão informacional e suas consequências na vida dos sujeitos envolvidos. No primeiro caso trata-se de pessoas que vivem na Era da Informação e, no entanto, sequer estão informadas disso ou se consideram dignas a isso. No segundo caso trata-se de uma pessoa que por ter tido acesso à leitura, mesmo muitos anos antes das revoluções tecnológicas da comunicação e da informação, já tinha a capacidade de imaginar ou idealizar um futuro de muitas informações disponíveis para todos.

Estes exemplos divergem da cultura ocidental e da atualidade desta, na qual alguns de nós vivemos, em meio à "avalanche tecnológica" e a facilidade de acesso à informação como aborda Moore (1999) ao tratar da evolução de um mundo onde a informação desempenha um papel extremamente significativo na vida econômica, social, cultural e política das pessoas.

De acordo com Castells (2003), as novas tecnologias da informação podem auxiliar bastante no desenvolvimento da sociedade, mas também é preciso analisar as questões negativas de toda esta transformação; a Internet, por exemplo, apesar de conectar grandes massas, exclui os que a ela não têm acesso; mesmo promovendo 
a partilha das informações e criando valores independentes da posição social do usuário, pois as interações virtuais e on-line também podem gerar isolamento.

Segundo Dominique Wolton (2008 apud MARTINS; SILVA, 2008, p.153), pesquisador francês:

[...] há somente de trezentos a quinhentos milhões de internautas no mundo, dos quais mais de $80 \%$ nos países do Norte, o que é suficiente para relativizar a ideia de revolução "para todos", [...] Vê-se que somente uma poderosa vontade política decidindo integrar a Internet a um projeto mais vasto poderia evitar que o desequilíbrio Norte-Sul se agrave.

Corroborando com esta discussão, Michel Maffesoli (2008 apud MARTINS; SILVA, 2008, p.23), professor da Universidade de Sorbonne em Paris, afirma que "[...] raramente a informação alcança todos ao mesmo tempo. Quase nunca ela é universal. Esse é um mito do jornalismo ocidental." Neste sentido Wolton afirma que a sociedade da informação corre o risco da mesmice, por favorecer a ligação entre indivíduos e comunidades que se parecem, sem ser heterogenia. Necessita-se do multicultural, das relações entre aqueles que não se parecem, o que é uma questão inteiramente política e não apenas técnica. (MARTINS; SILVA, 2008.)

Em publicação mais recente Castells (2009, apud MORAES, 2009) aborda novamente a questão das desigualdades utilizando-se do termo "divisória digital", neste sentido, - autor destaca que embora as pessoas sem acesso à Internet apresentem fragilidades na inserção no mercado de trabalho, os territórios não conectados acabam perdendo competitividade econômica internacional e desenvolvem aglomerados de pobreza nos países de terceiro mundo, por outro lado, existe um avanço considerável de acesso à Internet atualmente. Por isso a desigualdade está deixando de ser desencadeada pela conectividade técnica e torna-se uma questão de capacidade educativa e cultural de utilizar a Internet. Trata-se de:

[...] saber onde está a informação, como buscá-la, como transformá-la em conhecimento específico para fazer aquilo que se quer fazer. Essa 
capacidade de aprender a aprender; essa capacidade de saber o que fazer com o que se aprende; essa capacidade é socialmente desigual e está ligada à origem familiar, ao nível cultural, ao nível de educação. É aí que está empiricamente falando, a divisória digital neste momento. (MORAES, 2009, p. 267.)

Adentrando essa discussão, Wolton (2008) considera ser preciso integrar a Internet ao campo de debates políticos, possibilitando a reflexão crítica de seus usuários. Ressalta, portanto, a necessidade urgente em relançar uma reflexão sobre a democracia e a participação política a partir da Internet. Pois, segundo o autor, foram necessários 150 anos para humanizar o projeto industrial, o mesmo não pode ocorrer com a Internet:

A história ensina que o homem tem sempre uma incalculável capacidade de destruição em si mesmo. Se não se quer que as técnicas mais sofisticadas que o homem inventou sejam a oportunidade para uma nova desumanização, é preciso preservar o homem, suas fraquezas, suas forças e suas contradições. Porque só ele sonha o futuro, pensa sua história e dá sentido a sua experiência. (MARTINS; SILVA, 2008, p.155)

De acordo com Moore (1999), a sociedade da informação e do conhecimento apresenta três características fundamentais que são: A "informação como recurso econômico", tendo as empresas sempre em busca de maior eficácia, procurando cada vez mais informações. O "uso da informação pelo público", quando as pessoas utilizam a informação como cidadãos para exercer seus direitos e responsabilidades civis. E, ainda, a "informação na economia" que tem como função satisfazer a demanda geral de meios e de serviços de informação. Destacando-se que uma parte importante deste setor se refere à infra-estrutura tecnológica, redes de telecomunicação e computadores, além do desenvolvimento da indústria criadora da informação que circula nas redes, tais como os provedores, por exemplo.

O papel da informação e do conhecimento nesta nova sociedade, é proporcionar aos indivíduos embasamento para que possam obter o que lhes é garantido por direito. 
Pois a informação pode ajudar as pessoas a cuidar de suas próprias vidas, em matéria de saúde, proporcionando um meio de controle sobre a existência. Além disso, os consumidores bem informados podem fazer com que os fabricantes e os provedores de serviços sejam responsáveis por seus produtos. O acesso a informação e a formulação do conhecimento, portanto, garantem aos cidadãos entendimento sobre os assuntos públicos, a fim de possibilitar uma ideia mais precisa dos seus governantes (MOORE, 1999).

No âmbito dessa discussão, Pierre Lévy (2009) trata das novas práticas políticas possibilitadas pela Internet e destaca a liberdade e responsabilidade maior dos cidadãos. O autor levanta a hipótese de que por meio da revolução do "ciberespaço" se dará a reestruturação da esfera pública a nível mundial, repercutindo profundamente sobre a vida democrática das pessoas. Os internautas poderão se revelar cidadãos mais bem informados, politicamente mais ativos e mais conscientes. Trata-se do "cibercidadão". Segundo Lévy (2009 apud MORAES, 2009, p.381) é necessário desenvolver a cultura do diálogo porque "o ato essencial da democratização não é o voto, mas a deliberação, a saber, o exercício da inteligência coletiva na elaboração das leis e das grandes decisões políticas" que seria possível a nível mundial graças a Internet.

Castells (2003), por sua vez, pondera um pouco ao abordar essa questão, para ele, em princípio a Internet poderia ser um instrumento de participação cidadã extraordinário, entretanto, destaca que o que se tem visto nesse sentido são vias de informação unidirecional com o único objetivo de converter os cidadãos em eleitores potenciais e para que os partidos consigam recuperar informações para ajustar sua publicidade.

Pode-se inferir que as transformações tecnológicas, destacando-se a Internet e a WWW, representam ferramentas que a sociedade pode utilizar coletivamente de forma construtiva ou destrutiva na organização social e qualidade de vida dos indivíduos que compõem essa sociedade global. Isso vai depender do desenvolvimento político e cultural dessas sociedades. 
Nesse contexto pode-se dizer que as mídias representam ferramentas com significativo poder de influência na formação de opinião dos indivíduos. Assim, a grande imprensa pode ser entendida, atualmente, como uma coluna de sustentação do poder que organiza uma sociedade. Para alguns ela seria o quarto poder, além dos três poderes: executivo, legislativo e judiciário. Isso se dá porque na atual conjuntura brasileira a imprensa é imprescindível como fonte legitimadora das medidas políticas anunciadas pelos governantes, das estratégias de mercado das grandes corporações e pelo capital financeiro.

Pode-se inferir, conforme as palavras de José Arbex Jr. (2003 apud ABRAMO, 2003, p.8), que a imprensa “Constrói consensos, educa percepções, produz 'realidades' parciais apresentadas como a totalidade do mundo, mente, distorce os fatos, falsifica, mistifica [...]". Ou seja, a imprensa atua como um "partido" que defende os interesses específicos de seus proprietários privados, ignorando os interesses da população brasileira. Essa é a discussão central desse trabalho.

Em um país como o Brasil, ainda em desenvolvimento, sabe-se que as verbas governamentais não atingem a base da estrutura social, ou seja, a Educação. Isso faz com que a maior parte da população careça de preparo para lidar com tantos avanços tecnológicos e possibilidades de acesso a informação, bem como de capacidade para reflexão sobre tais informações. Neste contexto destaca-se a questão da exclusão ao acesso as novas tecnologias da informação e, portanto, a importância das mídias, principalmente a imprensa televisiva que representa o meio ou instrumento mediador da informação mais prático e popular no país, embora seja muito pouco utilizado para fins instrutivos, sendo geralmente adotado para manipulação em massa com finalidades comerciais e políticas.

Por isso, Mattelart e Mattelart (2003) questionam se a mídia é mediadora ou "antimediadora". Conforme os autores o que caracteriza os meios de comunicação de massa é o fato de esses serem "antimediadores", intransitivos e fabricantes da "nãocomunicação", ao considerar que a comunicação consiste na troca, na reciprocidade de uma fala. Desta forma o que predomina na relação entre mídias e indivíduos é o poder de dominação e regulação social. 
O processo pelo qual ocorre esse poder de dominação, através da formação de opinião pública, compreende um tipo de pensamento complexo descrito pelo sociólogo francês Edgar Morin (2000). O desafio da complexidade, consiste no fato de que toda informação tem apenas um sentido em relação a uma situação, assim, o sentido da palavra ou da imagem muda conforme o contexto, assim, para se conhecer não se pode isolar uma palavra ou uma informação, sendo necessário ligá-la a um contexto. Só se pode conhecer as partes conhecendo o todo em que se situam.

Complementando, Kanavillil Rajagopalan (2003), traz a ideia de que tudo pode e deve ser contestado, abordando também a questão dos termos de designação do discurso jornalístico na formação de opinião pública favorável ao mesmo; os eufemismos utilizados em função de minimizar a culpa dos responsáveis pelas tragédias ocorrentes no mundo e, ressaltando, ainda, o poder de designação de referência neutra, ao agregar valores através da nominação.

De acordo com Morin (2000) e Rajagopalan (2003), portanto, existe um pensamento complexo que inclui texto ou imagem e contexto e que está sempre presente nas informações transmitidas por meio das mídias. Desta forma os donos dos meios de comunicação são detentores de poder sobre a formação de opinião pública, de regulação da sociedade.

Stuart Hall (entrevista concedida a SOVIK, 2003, p. 354). define isso como um processo de codificação e de decodificação dos termos de linguagem, tratando do "ler entre linhas" como uma questão mais complexa do que a princípio pode parecer. Conforme o autor:

[...] "Codificação/Decodificação" [...] A mensagem é uma estrutura complexa de significado que não é tão simples como se pensa. A recepção não é algo aberto e perfeitamente transparente, que acontece na outra ponta da cadeia de comunicação. E a cadeia comunicativa não opera de forma unilinear. [ ] No contexto político existe, ainda, a noção [...] de que o significado não é fixo, de que não existe uma lógica determinante global que nos permita decifrar o significado ou o sentido 
ideológico da mensagem contra alguma grade. A noção de que o sentido sempre possui várias camadas, de que ele é sempre multirreferencial.

Os donos dos meios de comunicação utilizam-se das mídias como ferramentas para manipulação em massa. Para isso é adotado este processo de "pensamento complexo", no qual se dá a codificação e decodificação. Ou seja, cada mensagem codificada aparentemente pressupõe determinada decodificação, desta forma as informações transmitidas pelas mídias são codificadas exatamente da maneira que se deseja que elas sejam decodificadas ou interpretadas, de modo a influenciar, como bem entender, a opinião pública. Assim, somente os mais perspicazes ou bem instruídos conseguem ir além da aparente decodificação, adentrando o contexto político e a noção de que os significados não são fixos e de que nem tudo é o que parece ser. Por meio das mídias é possível estabelecer um forte poder de designação, de influência, até mesmo cultural, que muitas vezes acaba construindo a realidade social dos indivíduos.

Mattelart e Mattelart (2003) reportam-se para as teses de Foucault e trazem para essa discussão o modelo utópico de organização social em "Panóptico" que consiste em uma torre central de onde se pode controlar com plena visibilidade todo o círculo de um prédio dividido em alvéolos onde os vigiados encontram-se confinados em células individuais, separados uns dos outros, sendo vistos sem se ver. Trata-se de uma caracterização do modo de controle exercido pelo dispositivo televisual para organizar o espaço, controlar o tempo, vigiar o indivíduo e regular seus comportamentos. Neste caso as mídias televisivas representam o "Panóptico Invertido" no qual os vigiados podem ver sem ser vistos.

Para Morin (2000) "somos produtos produtores" o que significa que os indivíduos são produtores da sociedade porque sem indivíduos não existe sociedade, desta forma, a existência de uma sociedade com sua cultura, normas, leis, regras, etc. produz esses indivíduos. Ou seja, os indivíduos produzem a sociedade e a sociedade produz os indivíduos como um processo que se dá em um ciclo vicioso. Nisso consiste o pensamento complexo e o poder das mídias na regulação da sociedade por meio da disseminação de determinadas ideias, na produção de indivíduos produtores da 
sociedade ideal para os donos das mídias, para o sistema capitalista que estabelece uma sociedade de consumo, inclusive do consumo da informação e do conhecimento.

Isso significa ainda que damos vida às nossas ideias e, uma vez que Ihes damos vida, são elas que indicam o nosso comportamento, que nos mandam matar ou morrer por elas; vale dizer que tais produtos são os nossos próprios produtores [...] (MORIN, 2000, p. 25.)

Neste contexto e utilizando-se de termos como "comercialização do conhecimento" e "indústria cultural” Burke (2003) destaca que uma das razões para se afirmar que a sociedade atual pode ser definida como sociedade da informação é que a produção e a venda de informações contribui de maneira considerável para as economias mais desenvolvidas.

Segundo Morin (2000) o objetivo do pensamento complexo é contextualizar e globalizar. O que, na discussão da temática apresentada nesse trabalho, consiste no entendimento de quem é o indivíduo e do que é a sociedade, de qual a relação entre ambos e o que as mídias representam nessa relação. Uma vez compreendidas essas questões, os indivíduos podem ter autonomia e sabedoria na regulação da sociedade que constituem, de forma a se libertar um pouco das amarras de um sistema maior, que é o capitalismo com seu jogo de poderes políticos. Assim, entende-se que a sociedade da informação e do conhecimento representa uma época na qual é possível se informar para conhecer os indivíduos e o contexto no qual encontram-se inseridos, bem como alcançar o entendimento de como isso tudo ocorre, possibilitando reflexões que não se deixam manipular por meio de instrumentos midiáticos.

Nesse sentido Abramo (2003) destaca os padrões de manipulação adotados pela grande mídia brasileira, demonstrando como é possível refletir e não se deixar enganar por tudo o que se lê e/ou se vê publicado por aí.

Em 1994 verificou-se, mais do que nunca, a necessidade em se discutir a questão da manipulação midiática e a ética do jornalismo, quando ocorreu o conhecido, ou nem tão conhecido assim, caso da "síndrome da antena parabólica", conforme divulgado 
por Kucinski (1998). Tratava-se do incidente ocorrido nos bastidores do Jornal Nacional, da TV Globo, no decorrer da primeira disputa presidencial entre Luiz Inácio Lula da Silva e Fernando Henrique Cardoso, quando Rubens Ricupero, o então ministro da Fazenda, confidenciou ao jornalista Carlos Monforte sua falta de escrúpulos na campanha política, favorecendo Fernando Henrique.

Ocorre que esta conversa que deveria ser informal acabou sendo transmitida via satélite para antenas parabólicas em várias regiões do Brasil, fazendo com que os telespectadores tomassem conhecimento das falcatruas de políticos corruptos vinculados à imprensa manipuladora. Esse flagra, no entanto, não foi suficiente para que a falta de ética no jornalismo brasileiro tivesse um fim. Com a falta de regulação da imprensa, os donos dos meios de comunicação estão livres para atuar como bem entendem, inclusive utilizando-se de padrões de manipulação.

Neste sentido Ayoub (2006) mostra como a revolução industrial contribui para que os europeus se desvencilhassem de quase um século de censura e restrições à imprensa, enquanto no Brasil essa regulação ainda não existe. Segundo Ayoub (2006) a imprensa brasileira cumpre um papel enquanto representação de classe, ela defende seus interesses burgueses e ataca os que a contestam. Os proprietários dos meios de comunicação querem e exigem participação no poder, interferindo não apenas no embate ideológico, como também na disputa política e no processo eleitoral.

Assim, acontecimentos como o da "síndrome da antena parabólica", dentre muitos outros, refletem o porquê de a necessidade da sociedade brasileira aprender a ler e a decodificar as informações. Essa é a mensagem principal passada pelo experiente jornalista e professor Perseu Abramo, ao tratar a questão dos padrões de manipulação adotados pela grande imprensa brasileira.

Em seus estudos Abramo (2003) desmascara a dita objetividade da grande imprensa brasileira, mostrando que se trata de uma falsa objetividade, situando o jornalismo praticado como um instrumento de controle político das elites, contrário aos interesses maiores do povo brasileiro. Para o jornalista, a verdadeira motivação da empresa de 
comunicação em manipular a informação e distorcer a realidade está principalmente no campo político, na lógica do poder e, em um segundo plano, no campo econômico, na busca do lucro. Mas é bastante frequente, sempre distorcendo de alguma forma a realidade, como esclarece o autor:

A maior parte do material que a imprensa oferece ao público tem algum tipo de relação com a realidade. Mas essa relação é indireta. É uma referência indireta à realidade, mas que distorce a realidade. Tudo se passa como se a imprensa se referisse à realidade apenas para apresentar outra realidade, irreal, que é a contrafação da realidade real. É uma realidade artificial, não-real, irreal [...]. (ABRAMO, 2003, p.23).

As técnicas de manipulação utilizadas pela grande imprensa brasileira, de acordo com Abramo (2003), ocorrem às vezes de maneira sutil, contida, outras vezes, de modo escancarado, grosseiro e até mesmo agressivo, pois ainda não existe uma regulação dos meios de comunicação no Brasil. A manipulação da informação se converte, assim, em manipulação da realidade.

As técnicas de manipulação adotadas pela grande imprensa brasileira, conforme Abramo (2003) são as seguintes:

1. Padrão da Ocultação: Se refere à ausência e à presença dos fatos reais. Ocorre que muitas vezes acontece um deliberado silêncio sobre determinados fatos da realidade que são totalmente ignorados fazendo com que os leitores também os ignorem. Desta forma o fato real é eliminado da realidade e deixa de existir.

2. Padrão da Fragmentação: Neste caso a realidade é fragmentada em vários outros minúsculos fatos particularizados, muitas vezes irrelevantes, se comparados com os fatos reais, com o todo. $O$ fato real é fragmentado de forma que parte dele é isolada e apresentada fora do contexto original, de forma descontextualizada. Isso acaba gerando outros significados que não condizem com a realidade. Também pode ocorrer a invenção artificial e ficcional de outros fatos. 
3. Padrão da Inversão: Neste caso, depois do fato ser fragmentado e descontextualizado, ainda tem suas partes reordenadas e, portanto, invertidas. O que gera uma bagunça completa que já não representa mais qualquer aspecto da realidade. Trata-se de uma destruição da realidade original e criação de uma nova realidade que é absolutamente artificial.

Existem várias formas de inversão: Inversão da relevância dos aspectos, quando o secundário é apresentado como o principal e vice-versa; Inversão da forma pelo conteúdo que ocorre quando o texto ou a imagem passa a ser mais importante do que o fato que está reproduzindo; Inversão da versão pelo fato, quando não é o fato real que toma importância, mas a versão dos fatos apresentada pelo órgão de imprensa; Inversão da opinião pela informação, quando a informação real é totalmente substituída pela opinião do órgão de imprensa, neste caso o juízo de valor é utilizado como se fosse um juízo de realidade. Nestes casos, conforme destaca o autor, é importante frisar que:

Essa particular inversão da opinião sobre a informação pode às vezes assumir caráter tão abusivo e absoluto que passa a substituir a realidade real até aos olhos do próprio órgão de informação. Não é incomum perceber que às vezes os responsáveis pelos órgãos cometem erros - aí, sim, involuntários - porque passaram a acreditar integralmente nas matérias do próprio órgão, sem perceber que elas não correspondem à realidade. (ABRAMO, 2003, p. 32).

4. Padrão de Indução: Refere-se ao fato de que, submetido, ora mais ou ora menos, aos padrões de manipulação da imprensa, o leitor é induzido a ver o mundo da mesma forma que o órgão de imprensa o vê. Ou seja, o leitor é induzido a ver o mundo não como ele realmente é, mas sim como querem que ele o veja.

5. Padrão Global: Este padrão é considerado específico do jornalismo de televisão e de rádio. Divide-se em três momentos básicos: exposição do fato, apresentação da fala de cidadãos que compõem a sociedade, apresentação da opinião de um especialista ou uma autoridade no assunto. Tudo isso junto 
favorece a manipulação fazendo com que o telespectador ou o ouvinte seja induzido a acreditar em informações inventadas pelos donos das mídias.

Assim, é possível compreender como ocorre o processo de manipulação midiática e utilizar esses ensinamentos deixados por Perseu Abramo aplicando-os em pesquisas e estudos que objetivam a análise de textos, sons e imagens mediados pela grande imprensa brasileira, desfazendo possíveis tentativas de manipulação e esclarecendo os cidadãos de forma ética, responsável. E é importante frisar que esse papel não o papel de divulgação e mediação da informação não cabe apenas (de forma monopolizada) a grande imprensa, mas a todos. Talvez não seja injusto dizer que os profissionais mais significativos no cumprimento da mediação da informação são os professores e os bibliotecários. No próximo tópico destacamos o papel do bibliotecário nesse panorama.

\section{O PAPEL DO BIBLIOTECÁRIO NESSE PANORAMA}

Maria Nélida González de Gómez (2003), pesquisadora do Instituto Brasileiro de Informação em Ciência e Tecnologia (IBICT), faz o seguinte questionamento: "quais estruturas de informação poderiam sustentar os processos de formação, circulação e institucionalização do poder, em um horizonte democrático?". Considerando as reflexões que podem ser feitas a partir desta proposta, segue esse tópico.

A vida, que vai do poder à crítica do poder, está estruturada em um vasto universo de informações apresentadas em textos, imagens, multimídias etc. Grande parte da população não tem acesso a isto ou não sabe como desfrutar das possibilidades existentes. Aliás, ter acesso à informação não é garantia de crítica ou de inclusão informacional e social, mas aumenta a chance de se conhecer as regras do jogo do mundo da decodificação da informação. Esta parcela da sociedade tem muito mais chance de acreditar no que vê e ouve primariamente do que uma pessoa que recebeu instruções para uma competência informacional, que foi em graus variados introduzida no território da crítica e da desconstrução do mundo pela linguagem codificada. 
Para pensar mais as pessoas precisam se envolver com o pensamento de outros que, na prática cotidiana, as levam a rever o que elas mesmas pensam, ou a pensar diferente. Dialogar é construir um pensamento junto com o outro. É busca de encontro com o outro em nome de ideias e conceitos no intuito de entender mais, de almejar a compreensão, de superar as tentativas de manipulação.

Neste sentido é possível dizer que todas as pessoas podem se aproximar da ciência apenas pelo esforço de reflexão que constitui uma capacidade de todo ser pensante. Mas na sociedade da informação este esforço não pode acontecer sem mediação. Por isso, é importante que na escola, na universidade, na biblioteca, nas mídias, nas comunidades e instituições em geral, as pessoas sejam motivadas para o pensamento cuidadoso, aquele que cuida da análise e da crítica e luta contra a violência, seja do discurso, seja dos indivíduos, seja das instituições, seja das nações.

Desta forma as pessoas podem ser capacitadas no processo de decodificação informacional para enfrentar o conturbado mundo das informações, das tentativas de manipulações que fazem parte de um processo alienador que dificulta um entendimento aprofundado acerca das questões políticas nacionais e internacionais provenientes do período pós-guerra. Período em que se estabeleceu um nexo da informação com a política, destacando-se o poder de intervenção do Estado, já não apenas como dimensão de racionalidade administrativa, mas como fator estratégico do desenvolvimento científico-tecnológico, como enfatiza a autora:

Tendo essa competência de sobrecodificar e acumular excedentes de conhecimento e informação, um capital informacional (junto ao capital de força física e capital econômico) compõe o "metacapital" do Estado. (GONZÁLEZ DE GÓMEZ, 2002, p. 27)

Esse metacapital governamental tem um propósito, trata-se da conquista de poder, ou, de monopólio de um poder universal e absoluto. E aqui pode-se questionar o que um país é capaz de fazer para continuar sendo o detentor do poder. Quanto a isso o mundo já sofreu e sofre muitas atrocidades. Por isso, é importante dizer que na 
sociedade da informação a informação é um bem poderoso que pode ser utilizado de diversas maneiras, para o bem ou para o mal.

Desta forma, a ideia de "Governança Informacional" apresentada por (GONZÁLEZ DE GÓMEZ, 2002), com foco na inclusão digital, no direito a cidadania, com princípios de igualdade informacional e social (dispondo do acesso às novas tecnologias da informação e da comunicação, capacitação para decodificação da informação, preparo educacional para uma reflexão crítica da informação e produção de conhecimento), corresponde a uma estrutura de informação que poderia sustentar uma sociedade desejada do ponto de vista do cidadão comum.

Para tanto, tal estrutura governamental requereria escolas e universidades públicas ofertando ensino de qualidade, bibliotecas públicas preparadas para atender a demanda de forma satisfatória, programas governamentais de difusão e distribuição das novas tecnologias da informação para todos os cidadãos etc. Assim, essa "Governança Informacional" compreende transparência, abertura e acessibilidade. Nesse sentido, a política é a definição do bem comum, do cuidado com a comunicação, que é o cuidado com a condição humana em suas possibilidades coletivas de dignidade. Portanto, é por meio de políticas públicas de informação pautadas na responsabilidade social que a humanidade pode progredir verdadeiramente, ou seja, progredir humanamente e não apenas tecnologicamente. O que falta para que isso aconteça é os indivíduos sociais perceberem que as tecnologias são as suas ferramentas e não o contrário.

A postura do bibliotecário, (considerando aqui a sua identidade coletiva ou o coletivo), além de refletir sua formação profissional, também é decorrente do contexto atual da conjuntura política e social e das novas tecnologias em desenvolvimento contínuo. $O$ bibliotecário, conforme a fundamentação teórica desse trabalho; revela que a mediação da informação realizada de forma ética e profissional, sem manipulação dos detentores do poder, é extremamente relevante por agregar o comprometimento desse profissional com sua profissão, com os colegas de trabalho, com o desenvolvimento do processamento técnico da informação e com os usuários, ou seja, um comprometimento com a sociedade como um todo. 
O bibliotecário é extremamente importante nesse contexto porque é o mediador da informação. Mas é necessário união, força coletiva, ou seja, a classe precisa estar unificada, consolidada em uma identidade coletiva que possa gerar verdadeiras alternativas de busca para a solução desses problemas sociais. Essa busca consiste na discussão do assunto, de sua divulgação pela mídia e da adoção de políticas de ampla difusão da informação em texto escrito, o que como um conjunto de ações auxiliaria os governantes de todos os países desenvolvidos e em desenvolvimento, buscando, por fim, um panorama social onde a informação, voltado para o bem de todos os grupos da sociedade, sem distinções, prevaleça como auxílio no progresso social.

Uma das razões para o fraco engajamento político e busca de desenvolvimento social por parte do bibliotecário pode ser a ação dos Cursos de Biblioteconomia e áreas afins. Pois em muitos casos ocorre que a inserção do tema nos currículos educacionais ainda é escassa ou nula, predominando uma Biblioteconomia tecnicista que pouco ou nada discute sobre as políticas públicas de informação e tecnologia.

Assim, uma atuação dos Cursos de Biblioteconomia voltada à maior inclusão da temática em seus projetos pedagógicos, bem como uma mais ampla inserção do tema em âmbito nacional e internacional como objeto de pesquisa, poderá melhorar esse cenário da Ciência da Informação e da Biblioteconomia no Brasil.

\section{CONSIDERAÇÕES FINAIS}

Com relação às novas tecnologias da informação e da comunicação e considerando as variáveis procuramos destacar os pontos positivos decorrentes do acesso à informação e às novas tecnologias informacionais e comunicacionais que se apresentam na sociedade, bem como o vislumbramento de ações positivas nesse contexto, além de meios que impossibilitem ações de caráter negativo.

Infelizmente muito conteúdo disponível na Internet pode ser consultado e utilizado de formas negativas. Sabe-se, por exemplo, que grande parte do conteúdo disponível na WEB é pornográfico, incluindo contatos para prostituição, tráfico de pessoas, drogas 
e armas. Pedófilos também utilizam a Internet como meio de aproximação de suas vítimas, além de golpistas que aproveitam as redes de relacionamento que gerenciam encontros românticos. Pessoas com transtornos psicológicos depressivos buscam informações e até apoio de outras pessoas que as influenciam virtualmente.

Também existem os casos de reflexo de preconceitos culturais que se propagam largamente na Internet, diferentemente de algumas décadas atrás quando tais informações tinham um poder de difusão bastante limitado. É o caso, por exemplo, de racismo regional, tal qual a repercussão da estudante universitária de São Paulo que divulgou em seu tuiter algo que impactou o país, ao afirmar que os nordestinos deveriam ser afogados, pois não tinham valor algum para o Brasil.

Podemos citar alguns exemplos positivos do advento da sociedade da informação e da propagação de acesso às novas tecnologias da informação e da comunicação. Um bom exemplo pode ser o caso recente da chamada "A Rede Social que Mudou o Mundo", documentário apresentado pela Discovery Channel, demostrando como jovens utilizaram o facebook na luta contra a tirania de Kadafi. Fatos como esse se destacam mundialmente sendo considerados como grandes conquistas, já que, maior parte dos regimes políticos mundiais, ainda é de caráter totalitário, enquanto a menor parte consiste em democracias plenas, estando o Brasil, nesse caso, entre os países classificados, segundo a The Economist, como democracias frágeis.

Assim, o que pretendemos destacar nesse trabalho, são as ações positivas, pois, consideramos que com a implementação e contínua reavaliação que regulamente as políticas públicas de informação e tecnologia no país, as mídias podem ser utilizadas para evitar as questões negativas anteriormente citadas e dar ênfase para a miríade de coisas boas que o acesso as mídias podem proporcionar para a sociedade. Como por exemplo, acesso a informações de qualidade que priorizem a humanização e não os preconceitos e intolerâncias, prestação de contas das políticas do país, disponibilidade de informações culturais que fortaleçam a abrangência dessa nação de grandes dimensões e regiões geográficas com belezas distintas, povos com culturas belíssimas, artesanatos variados etc. Informações sobre como utilizar as novas tecnologias, interfaces amigáveis, acessibilidade para os usuários na busca e 
encontro de informações sobre saúde pública, economia doméstica, investimentos financeiros, educação e bolsas de estudo, cursos online e sites com esclarecimentos sobre os eventos da cidade onde moram, informações sobre os direitos e deveres de todo cidadão, cuidados com os animais, inclusive a disponibilização de informações sobre a qualidade e proveniência dos produtos consumidos, evitando maus tratos aos animais com produção em massa e abate cruel na "indústria da carne", na utilização de testes desnecessários em animais, atitudes terríveis que resultam da sociedade capitalista, do consumo exacerbado, na qual as indústrias estão sempre visando lucro sem se importar com a exploração de outros seres humanos ou com os direitos dos animais etc.

Para finalizar, destacamos o papel do bibliotecário como disseminador e mediador da informação e da necessidade de um maior engajamento desses profissionais na elaboração e implementação de políticas públicas de informação e tecnologia. Consideramos que o Livro Verde deve ser prioridade na biblioteconomia brasileira, de forma que o seu "amadurecimento", sua transformação em Livro Branco se concretize, de forma que as políticas públicas de informação sejam muito bem trabalhadas por esses profissionais, apresentadas ao governo e quando aprovadas, (pois devem ser aprovadas, devido sua importância e urgência para o progresso econômico e social brasileiro), que todo o trabalho efetuado não seja abandonado como algo que se fará por si só, se retroalimentando conforme as transformações sociais vão ocorrendo, mas que seja devidamente acompanhado e atualizado pelos profissionais da área, garantindo uma verdadeira sociedade da informação e do conhecimento.

\section{REFERÊNCIAS}

ABRAMO, P. Padrões de manipulação na grande imprensa. São Paulo: Editora Fundação Perseu Abramo, 2003.

AYOUB, A. H. Mídia e movimentos sociais: a satanização do MST na Folha de São Paulo. 2006. 169 p. Dissertação (Mestrado em Ciências Sociais) - Universidade Estadual de Londrina, Londrina, PR. 
BRASIL. Ministério da Cultura. Plano Nacional do Livro e Leitura. 2005. Disponível em: <http://189.14.105.211/Default.aspx>. Acesso em: 02 maio de 2013.

BURKE, P. Uma história social do conhecimento: de Gutenberg a Diderot. Rio de Janeiro: Zahar Ed., 2003.

CARVALHO, A. M. G. A apropriação da informação: um olhar sobre as políticas públicas sociais de inclusão digital. 2010. 169 f. Tese (Doutorado em Ciência da Informação) - Faculdade de Filosofia e Ciências, Universidade Estadual Paulista, Marília, 2010.

CASTELLS, M. A galáxia da internet. Rio de Janeiro: Jorge Zahar, 2003.

CASTELLS, M. Internet e sociedade em rede. In: MORAES, Denis de (Org.). Por uma outra comunicação: mídia, mundialização cultural e poder. 2009, p.255-287.

CUBILLO, J. Políticas públicas de información en América Latina: Cuando nos hemos renovado? DataGramaZero - Revista de Ciência da Informação, v. 4, n. 4, agost./2003.

DECLARAÇÃO UNIVERSAL DOS DIREITOS HUMANOS. Assembléia Geral das Nações Unidas, $1948 . \quad$ Disponível em: $<$ http://portal.mj.gov.br/sedh/ct/legis_intern/ddh_bib_inter_universal.htm>. Acesso em: 28 abr. 2013.

FERREIRA, R. da S. A sociedade da informação no Brasil: um ensaio sobre os desafios do Estado. Ciência da Informação, v. 32, n. 1, p. 36-41, jan./abr. 2003.

GONZÁLEZ DE GÓMEZ, M. N. Informação: dos estoques às redes. Ciência da Informação, Brasília, v.24, n.1, 1995.

GONZÁLEZ DE GÓMEZ, M. N. Novos cenários políticos para a informação. Ciência da Informação, Brasília, v.31, n.1, p.27-41, jan./abr.2002. 
GONZÁLEZ DE GÓMEZ, M. N. As relações entre ciência, estado e sociedade: um domínio de visibilidade para as questões da informação. Ciência da Informação, Brasília, v.32, n.1, p.60-76, jan./abr.2003.

JARDIM, J. M. Sistemas e políticas públicas de arquivos no Brasil. Niterói: EDUFF, 1995.

KUCINSK, B. A síndrome da antena parabólica: ética no jornalismo brasileiro. São Paulo, Editora Fundação Perseu Abramo, 1998.

LEVY, P. Pela ciberdemocracia. In: MORAES, Denis de (Org.). Por uma outra comunicação: mídia, mundialização cultural e poder. 2009, p. 367-384.

LIRA, A. S. X.; OLIVEIRA, J. M. Política pública de informação na pespectiva do controle social na ciência da informação: o caso do programa é pra ler da Prefeitura Municipal de João Pessoa. Biblionline, v. 1, n. 2, 2005.

MAFFESOLI, M. A comunicação sem fim. In: MARTINS, Francisco Menezes; SILVA, Juremir Machado da (Org.). A genealogia do virtual. 2008, p.20-32.

MANGUEL, A. A biblioteca à noite. São Paulo: Companhia das Letras, 2006. 300p.

MATTELART, A.; MATTELART, M. História das teorias da comunicação. 6. ed. São Paulo: Loyola, 2003.

MONTVILLOF, V. Políticas Nacionales de Información: manual sobre formulación, aplicación y funcionamiento de una política nacional sobre la información. Paris: UNESCO, 1990. 169 p.

MOORE, N. A sociedade da informação. In: INSTITUTO BRASILEIRO DE INFORMAÇÃO EM CIÊNCIA E TECNOLOGIA. A informação: tendências para o novo milênio. Brasília, 1999. p.94-1008.

MORIN, E. Da necessidade de um pensamento complexo. In: MARTINS, Francisco Menezes; SILVA, Juremir Machado da (Org.). Para navegar no século XXI: 
tecnologias do imaginário e cibercultura. 2. ed. Porto Alegre: EDIPUCRS, 2000. p.1942.

NEVES, B. C. Análise das políticas de informação: sociedade da informação com foco na inclusão digital do global ao local. Rev. iberoam. cienc. tecnol. soc.,v. 5,n. 15, set./2010.

RAJAGOPALAN, K. Designação: a arma secreta, porém incrivelmente poderosa, da mídia em conflitos internacionais. In: Por uma linguística crítica: linguagem, identidade e a questão ética. São Paulo: Parábola Editorial. 2003.

SECCHI, L. Políticas públicas: conceitos, esquemas de análise, casos práticos. Capítulo 3 - Ciclo de políticas públicas. UDESC/ESAG, 2012. 27 slides, color.

SECCHI, L. Capítulo 3 - Ciclo de políticas públicas. UDESC/ESAG, [20-?]. color.

SEIERSTAD, A. O livreiro de Cabul. 3. ed. Rio de Janeiro: Record, 2006. 196p.

SOVIK, L. (Org.). Reflexões sobre o modelo de codificação/decodificação: uma entrevista com Stuart Hall. In: HALL, Stuart. Da diáspora: identidades e mediações culturais. Belo Horizonte: Editora UFMG; Brasília: Representação da UNESCO no Brasil, 2003.

TAKAHASHI, T. (Org.) Sociedade da informação no Brasil: livro verde. Brasília: Ministério da Ciência e Tecnologia, 2000. 195 p.

UHLIR, P. F. Diretrizes políticas para o desenvolvimento e a promoção da informação governamental de domínio público. Brasília: UNESCO, 2006. 69 p.

WOLTON, D. Pensar a Internet. In: MARTINS, Francisco Menezes; SILVA, Juremir Machado da (Org.). A genealogia do virtual. 2008, p.149-156.

Enviado: Fevereiro, 2020.

Aprovado: Junho, 2020. 